\title{
Phenotypic characterization of Astragalus glycyphyllos symbionts and their phylogeny based on the 16S rDNA sequences and RFLP of 16S rRNA gene
}

\author{
Sebastian Gnat • Magdalena Wójcik • \\ Sylwia Wdowiak-Wróbel · Michał Kalita • \\ Aneta Ptaszyńska $\cdot$ Wanda Małek
}

Received: 21 February 2014/Accepted: 24 March 2014/Published online: 8 April 2014

(C) The Author(s) 2014. This article is published with open access at Springerlink.com

\begin{abstract}
In this study, the nitrogen fixing Astragalus glycyphyllos symbionts were characterized by phenotypic properties, restriction fragment length polymorphism (RFLP), and sequences of $16 \mathrm{~S}$ rDNA. The generation time of A. glycyphyllos rhizobia in yeast extract mannitol medium was in the range $4-6 \mathrm{~h}$. The studied isolates exhibited a low resistance to antibiotics, a moderate tolerance to $\mathrm{NaCl}$, assimilated di- and trisaccharides, and produced acid in medium containing mannitol as a sole carbon source. In the cluster analysis, based on 86 phenotypic properties of A. glycyphyllos symbionts and the reference rhizobia, examined isolates and the genus Mesorhizobium strains were placed on a single branch, clearly distinct from other lineages of rhizobial genera. By the comparative analysis of $16 \mathrm{~S}$ rRNA gene sequences and 16S rDNA-RFLP, $A$. glycyphyllos nodulators were also identified as the
\end{abstract}

\section{S. Gnat}

Department of Veterinary Microbiology, University of Life Sciences, 12 Akademicka st., 20-033 Lublin, Poland

M. Wójcik · S. Wdowiak-Wróbel · M. Kalita .

W. Małek $(\square)$

Department of Genetics and Microbiology, University of Maria Curie-Skłodowska, 19 Akademicka st., 20-033 Lublin, Poland

e-mail: wanda.malek@poczta.umcs.lublin.pl

\section{A. Ptaszyńska}

Department of Botany and Mycology, University of Maria Curie-Skłodowska, 19 Akademicka st., 20-033 Lublin, Poland members of the genus Mesorhizobium. On the $16 \mathrm{~S}$ rDNA sequence phylogram, the representatives of $A$. glycyphyllos nodule isolates formed a robust, monophyletic cluster together with the Mesorhizobium species at $16 \mathrm{~S}$ rDNA sequence similarity of these bacteria between 95 and $99 \%$. Similarly, the cluster analysis of the combined RFLP-16S rDNA patterns, obtained with seven restriction endonucleases, showed that A. glycyphyllos rhizobia are closely related to the genus Mesorhizobium bacteria. The taxonomic approaches used in this paper allowed us to classify the studied bacteria into the genus Mesorhizobium.

Keywords Astragalus glycyphyllos symbionts Phenotypic properties $\cdot 16 \mathrm{~S}$ rDNA sequence analysis · Phylogeny

\section{Introduction}

The Fabaceae is one of the largest families of the flowering plants with nearly 19,000 species distributed throughout the world (Allen and Allen 1981). Most of these plants exhibit a unique ability to induce the root and/or stem nodules and establish symbiotic interaction with the soil bacteria called rhizobia. Inside nodules, rhizobia convert nitrogen from atmosphere into ammonium which is assimilated by plant (Haag et al. 2013; Perret et al. 2000). Due to agricultural and ecological importance of $\mathrm{N}_{2}$ fixing nodule bacteria, 
their diversity and taxonomy have been investigated extensively and, in a consequence, the Rhizobium systematics has been greatly improved in the last three decades. At the present time, 150 Rhizobium species have been identified and assigned to 12 genera of the class alpha-Proteobacteria i.e. Azorhizobium, Bradyrhizobium, Mesorhizobium, Rhizobium, Ensifer, Methylobacter, Devosia, Ochrobactrum, Blastobacter, Microvirga, Shinella, and Phyllobacterium as well as to four genera of the class beta-Proteobacteria i.e. Burkholderia, Cupriavidus, Herbaspirillum, and Ralstonia (Balachandar et al. 2007; Małek and Sajnaga 1999; Parte 2014; Sawada et al. 2003; Willems 2006).

Currently, in the Rhizobium taxonomy the polyphasic approach, based on phenotypic and genomic criteria is used (Graham et al. 1991; Małek and Sajnaga 1999; Vandamme et al. 1996). Among the phenotypic features especially interesting are those that are important in the ecological niche occupied by a given microorganism. For the classification of bacteria, mainly at the genus level and for tracing their evolutionary history, the analysis of full-length 16S rRNA gene sequences of a few carefully selected strains and restriction fragment length polymorphism (RFLP)-16S rDNA fingerprints of large number of strains are recommended (Mierzwa et al. 2009; Safronova et al. 2014; Smibert and Krieg 1981; Toolarood et al. 2012; Vinuesa et al. 2005; Wdowiak-Wróbel and Małek 2010; Wolde-meskel et al. 2005).

Most taxonomic studies of rhizobia have been focused on the symbionts of the crop legumes of agricultural significance but in the recent years the essential contribution in this field had the investigations of the symbionts of the wild growing legumes which are plants ecologically important.

Astragalus glycyphyllos, commonly known as the liquorice milkvetch, is a perennial, herbaceous, leguminous plant widespread throughout Europe and temperate Asia, important to maintain the proper ecosystem functioning. To the best of our knowledge, this is the first report concerning the genus position and evolutionary history of diazotrophic symbionts of A. glycyphyllos inferred from numerical analysis of phenotypic properties and comparative sequence analysis of $16 \mathrm{~S}$ rDNA. In order to determine the genus position and phylogeny of rhizobia associated with $A$. glycyphyllos, we isolated them from liquorice milkvetch root nodules and characterized by series of cultural, physiological, and biochemical tests as well as by sequence and RFLP analyses of the amplified 16S rRNA gene.

\section{Materials and methods}

Bacterial strains and their maintenance

All strains used in this study are listed in Table 1. Rhizobia were isolated from the root nodules of $A$. glycyphyllos growing in the xerothermic grasslands of south-east part of Poland (Lublin region), although, they could be also found in bulk soil. Nodule bacteria were routinely grown at $28{ }^{\circ} \mathrm{C}$ (unless otherwise noted) and stored at $4{ }^{\circ} \mathrm{C}$ on yeast extract mannitol medium (YEM $10 \mathrm{~g}$ of active dried Baker's yeast, $10 \mathrm{~g}$ of mannitol, $2.5 \mathrm{~g}$ of peptone, $15 \mathrm{~g}$ of agar, $11 \mathrm{of}$ deionized water). In phenotypic growth tests on various carbon an nitrogen sources minimal BS medium (Sherwood 1970) was used. Organic substrates were added to the medium after filter sterilization (pore size, $0.22 \mu \mathrm{m}$, Millipore Corporation).

Isolation of bacteria from A. glycyphyllos root nodules

The fresh nodules were dissected from the roots, rinsed thoroughly in water, surface sterilized by immersion in a $0.1 \% \mathrm{HgCl}_{2}$ for $1 \mathrm{~min}$, next in $0.75 \%$ ethanol for $1 \mathrm{~min}$, and rinsed in sterile water. Nodules were individually crushed, material from nodules was streaked onto the surface YEM plates, and the plates were incubated at $28{ }^{\circ} \mathrm{C}$ for 5-7 days. Individual colonies were selected and their purity was checked by repeated striking of single colonies on YEM medium. The symbiotic ability of each $A$. glycyphyllos nodule isolate was confirmed by nodulating its original host using the method of Vincent (1970).

Morphological and growth characteristics of bacteria

The nodule bacteria were examined for Gram reaction, structure of colonies, their color, consistency, and presence or absence of gummy substances (Smibert and Krieg 1981). The generation time of A. glycyphyllos rhizobia, their growth temperature ranges (5, 
Table 1 Bacterial strains used in this study

ZGM Department of Genetics and Microbiology, University of Marie Curie-Skłodowska, Lublin, Poland, USDA United States Department of

Agriculture, Beltsville, MD, USA, ATCC American Type Culture Collection, Rockville, $\mathrm{MD}$, ICMP International Collection of Microorganisms from Plants, Landcare

Research, Auckland, New

Zealand, $L M G$ Belgian

Coordinated Collections of

Microorganisms/LMG Bacteria

Collection, Gent Universiteit,

Belgium, CCBAU Culture

Collection of Beijing

Agricultural University,

Beijing, China, $I C h B$ Institute

of Bioorganic Chemistry,

Poznań, Poland, NZP Division

of Scientific and Industrial

Research, Palmerston North,

New Zealand, $D B$ Department

of Biotechnology, Graduate

School of Engineering, Osaka

University, Yamadaoka,

Suitashi, Osaka, Japan

\begin{tabular}{|c|c|c|c|}
\hline Strains & Host & Geographic origin & Source \\
\hline Astragalus glycyphyllos isolates AG1-29 & Astragalus glycyphyllos & Poland & ZGM \\
\hline Mesorhizobium albiziae CCBAU61158 & Albizia kalkora & China & CCBAU \\
\hline Mesorhizobium amorphae ICMP15022 & Amorpha fruticosa & New Zealand & ICMP \\
\hline Mesorhizobium caraganae CCBAU11299 & Caragana spp. & China & CCBAU \\
\hline Mesorhizobium chacoense USDA4963 & Prosopis alba & Argentina & USDA \\
\hline Mesorhizobium ciceri $\mathrm{UPMCa}^{\mathrm{T}}\left(\mathrm{ATCC} 51585^{\mathrm{T}}\right)$ & Cicer arietinum & Spain & ATCC \\
\hline Mesorhizobium ciceri USDA3383 & Cicer arietinum & Spain & USDA \\
\hline Mesorhizobium gobiense CCBAU83330 & Oxytropis glabra & China & CCBAU \\
\hline Mesorhizobium huakuii USDA4779 & Astragalus sinicus & China & USDA \\
\hline Mesorhizobium loti USDA3471 & Lotus corniculatus & New Zealand & USDA \\
\hline Mesorhizobium plurifarium USDA3707 & Acacia senegal & Senegal & USDA \\
\hline Mesorhizobium septentrionale SDW018 & Astragalus adsurgens & China & CCBAU \\
\hline Mesorhizobium shangrilense CCBAU65327 & Caragana bicolor & China & CCBAU \\
\hline Mesorhizobium temperatum LMG23931 & Astragalus adsurgens & China & LMG \\
\hline Mesorhizobium tianshanense USDA3592 & Glycyrrhiza pallidiflora & China & USDA \\
\hline \multicolumn{4}{|l|}{ Bradyrhizobium japonicum } \\
\hline USDA110 & Glycine max & USA & USDA \\
\hline USDA6 & Glycine $\max$ & USA & USDA \\
\hline Bradyrhizobium liaoningense USDA 3622 & Glycine $\max$ & USA & USDA \\
\hline Bradyrhizobium sp. (Lupinus) USDA3045 & Lupinus sp. & USA & USDA \\
\hline Bradyrhizobium yuanmingense CCBAU 10071 & Lespedeza cuneata & China & CCBAU \\
\hline \multicolumn{4}{|l|}{ Rhizobium galegae } \\
\hline HAMBI1141 & Galega officinalis & New Zealand & HAMBI \\
\hline HAMBI1 155 & Galega orientalis & & HAMBI \\
\hline HAMBI1185 & Galega officinalis & & HAMBI \\
\hline \multicolumn{4}{|l|}{ Rhizobium leguminosarum } \\
\hline bv. trifolii 21 & Trifolium sp. & Poland & ZGM \\
\hline bv. trifolii ANU843 & Trifolium sp. & Poland & ZGM \\
\hline bv. viciae 1 & Vicia sp. & Poland & ZGM \\
\hline bv. viciae 2 & Vicia sp. & Poland & ZGM \\
\hline bv. viciae 33 & Vicia sp. & Poland & ZGM \\
\hline bv. viciae 36 & Vicia sp. & Poland & ZGM \\
\hline bv. viciae 3841 & Vicia sp. & Poland & ZGM \\
\hline Rhizobium tropici OUT21 & Phaseolus sp. & USA & USDA \\
\hline \multicolumn{4}{|l|}{ Sinorhizobium fredii } \\
\hline USDA1-6 & Glycine sp. & China & USDA \\
\hline USDA16-1 & Glycine sp. & China & USDA \\
\hline USDA440 & Glycine sp. & China & USDA \\
\hline \multicolumn{4}{|l|}{ Ensifer meliloti } \\
\hline SU47 & Medicago sativa & Australia & NZP \\
\hline 11 & Medicago sativa & Poland & ZGM \\
\hline 13 & Medicago sativa & Poland & ZGM \\
\hline L5-30 & Medicago sativa & Poland & ZGM \\
\hline L54 & Medicago sativa & Poland & ZGM \\
\hline MVII & Medicago sativa & Poland & ZGM \\
\hline Agrobacterium tumefaciens B6S3 & & Poland & $\mathrm{IChB}$ \\
\hline
\end{tabular}


$\left.12,15,20,28,35,40,42,45^{\circ} \mathrm{C}\right)$, the ability to grow at various $\mathrm{pH}(4,5,6,7,8,9,10)$, tolerance for different $\mathrm{NaCl}$ concentrations $(0.1,0.5,1.0,1.5,2.0,2.5,3.0 \%)$ were performed on YEM medium as described by Smibert and Krieg (1981). The active movement of bacteria was assessed on $0.3 \%$ YEM agar medium by their capacity to migrate away from the spot of inoculation.

\section{Utilization of carbon sources}

Assimilation of different substrates as a sole carbon sources was tested on BS agar medium (Sherwood 1970) where mannitol was replaced by other carbon compound at the final concentration of $1 \%(\mathrm{w} / \mathrm{v})$. The following carbon substrates were tested: L-alanine, Larabinose, DL-arginine hydrochloride, DL-asparagine, cellobiose, dextrin, dulcitol, fructose, galactose, glycerol, glucose, L-glutamine, hippurate, inulin, sodium malate, xylose, tertrate, lactose, lysine, maltose, mannitol, mannose, raffinose, rhamnose, sucrose, sodium citrate, salicin, starch, trehalose, and tyrosine. The $\mathrm{pH}$ of medium was adjusted to 7.0 by using sterile $1 \mathrm{M} \mathrm{NaOH}$ or $1 \mathrm{M} \mathrm{HCl}$ after the carbon source was added. Bromothymol blue at the final concentration of $0.0025 \%(\mathrm{w} / \mathrm{v})$ was used as $\mathrm{pH}$ indicator. Changes in the $\mathrm{pH}$ values of the media were recorded after 5-7 days of bacterial growth at $28^{\circ} \mathrm{C}$. The BS medium with mannitol was used as the positive control whereas BS medium without any carbon source as negative one.

\section{Utilization of nitrogen sources}

Utilization of different substrates as a sole nitrogen was tested by using the basal BS medium in which $\mathrm{NH}_{4} \mathrm{Cl}$ was replaced by the following amino acids: DLarginine, DL-glutamine, L-histidine monohydrochloride, L-hydroxyproline, isoleucine, L-methionine, DLproline, DL-serine, L-tyrosine and $\mathrm{NaNO}_{3}$. All nitrogen sources were prepared as a stock solutions and added to the medium to obtain the final concentration of $1 \%$. The growth of bacteria in BS basal medium served as a positive control.

Intrinsic antibiotic resistance

Intrinsic antibiotic resistance was tested as described earlier (Kalita and Małek 2004) on YEM agar medium supplemented with one of the following antibiotics at the indicated concentrations $\left(\mu \mathrm{g} \mathrm{ml}^{-1}\right)$ : ampicillin 50 , 100, 200; neomycin 10, 20, 40, 80; streptomycin 25, 50, 100, 200; tetracycline 5, 10, 20, 40; rifampicin 10, 20, 40, 100.

\section{Tolerance to dyes}

Tolerance to dyes was investigated on YEM agar medium containing the following dyes at the indicated concentrations $(\%, \mathrm{w} / \mathrm{v})$ : auramine $0.0065,0.013,0.2$; safranin $0.0065,0.013,0.2$; methyl green 0.0065 , $0.013,0.2$; methyl red $0.0065,0.013,0.2$; crystal violet $0.0065,0.013,0.2$; acridine orange $0.0065,0.013,0.2$. The positive control for antibiotic and dye tolerances was the bacterial growth on the basal YEM medium under a standard conditions.

\section{Miscellaneous other tests}

Calcofluor and Congo red absorption were tested in YEM medium as described earlier (Wdowiak-Wróbel and Małek 2000). The precipitation of calcium glycerophosphate was examined according to Hofer's procedure (1941). Melanin production was studied using the method described by Cubo et al. (1998). The reaction to litmus milk, tests for activity of catalase, $\beta$ galactosidase, $\beta$-D-glucosidase (aesculinase), nitrate reductase, oxidase, peroxidase, phosphatase, and urease were carried out by the methods of Cowan and Steel (1965) whereas the indole acetic acid synthesis was studied according to method of Minamisawa and Fukai (1991). All phenotypic tests were done in triplicate at least twice.

\section{Data analysis}

In all experiments, the growth of bacteria was recorded after 5-7 days of incubation at $28{ }^{\circ} \mathrm{C}$ in triplicate. The results of phenotypic tests were coded using a binary system which was used to estimate the simple matching similarity coefficient (SM) of each strain pair and to generate a similarity matrix (Sneath and Sokal 1973). On the basis of the similarity matrix, clustering analysis was performed by the unweighted pair group method averages algorithm (UPGMA) with NT-SYS software package and results were visualized on the phenogram using NT-SYS software. 
DNA isolation

$30 \mathrm{ml}$ of $72 \mathrm{~h}$ Rhizobium liquid cultures in YEM medium were used to isolate genomic DNA according to the method described by Pitcher et al. (1989). The purity and concentration of DNA samples were assessed with spectrophotometer (Bio-Rad, SmartSpec $^{\mathrm{TM}} 3000$ ).

16S rRNA gene amplification

Primers fD1 (5'-AGAGTTTGATCCTGGCTCAG-3') and rD1 (5'-AAGGAGGTGATCCAG CC-3'), corresponding to Escherichia coli 16S rRNA gene position 8-27 and 1,524-1,540, respectively were used for PCR amplification of almost full-length 16S rDNA of studied bacteria (Weisburg et al. 1991). Amplification with 50-100 ng of pure genomic DNA was carried out according to ReadyMix ${ }^{\mathrm{TM}}$ Taq PCR Reaction Mix procedure (SIGMA-Aldrich) by using the following temperature profiles: initial denaturation at $96{ }^{\circ} \mathrm{C}$ for $2 \mathrm{~min} ; 30$ cycles of $40 \mathrm{~s}$ at $94{ }^{\circ} \mathrm{C}, 40 \mathrm{~s}$ at $52{ }^{\circ} \mathrm{C}, 1 \mathrm{~min}$ at $72{ }^{\circ} \mathrm{C}$; followed by a final extension at $72{ }^{\circ} \mathrm{C}$ for $3 \mathrm{~min}$ and then a hold at $4{ }^{\circ} \mathrm{C}$. To evaluate the effectiveness of PCR reaction, five microliter portions of amplified DNA were separated electrophoretically on a $1.5 \%$ agarose gel at approximately $80 \mathrm{~V}$. Remaining part of PCR products was purified and sequenced from both strands with the BigDye terminator Cycle Sequencing kit following manufacturer's instructions (Applied Biosystem, Foster City, CA, USA) and using the 3500 Genetic Analyzer (Applied Biosystems). The amplified 16S rDNA sequences of A. glycyphyllos symbionts and those of related bacteria obtained from GenBank were aligned using ClustalW 1.83 package and next, edited with the GeneDoc. Phylogenetic trees were generated using neighborjoining (NJ) and maximum likelihood (ML) methods. In the NJ method, the phylogenetic distances were determined with Kimura's two-parameter model (1980) using MEGA 4 program (Tamura et al. 2007). ML analysis was performed using PAUP version 4.0b10 (Swofford 2002) and MODELTEST 3.7 program (Posada and Crondall 1998) to choose the best-fit evolutionary model for $16 \mathrm{~S}$ rRNA gene. The confidence values for nodes in the tree were generated by bootstrap analysis using 100 permutations of the data sets.
16S rDNA nucleotide sequence accession numbers

The 16S rDNA sequences of 10 A. glycyphyllos symbionts have been deposited in GenBank nucleotide sequence databases under accession numbers: KF430327-KF430336.

\section{S rDNA PCR-RFLP}

Nearly full-length $16 \mathrm{~S}$ rDNA PCR products, obtained as described above, were digested with $5 \mathrm{U}$ each of MspI, MboI, Hin6I, HinfI, TaqI, RsaI, and AluI endonucleases and the restriction fragments were electrophoretically separated in $3 \%(\mathrm{w} / \mathrm{v})$ agarose gels. The RFLP profiles obtained with seven enzymes were combined and used for establishing RFLP groups. The isolates that had identical banding patterns were allocated to the same 16S rDNA-RFLP type. Relationships between strains were determined by using data from enzymes that differentiated strains. A binary system ( 1 for the presence of band and 0 for its absence) was used to generate similarity matrix which was analyzed using the unweighted pair group method with averages algorithm (UPGMA; Sneath and Sokal 1973) and dendrogram, presenting the 16S rDNA-RFLP clusters, was generated from the pairwise similarity matrix with NTSYS-PC software using the Nei and Li (1979) correlation coefficient.

\section{Results and discussion}

In the recent years, the clear progress towards the development of more complete rhizobial taxonomy has been made and new species of nodule bacteria have been described (Balachandar et al. 2007; http:// rhizobia.co.nz/taxonomy/rhizobia.html; Sawada et al. 2003; Willems 2006). The present studies, has focused on the analysis of rhizobia isolated from root nodules of wild growing A. glycyphyllos in order to determine their genus position and phylogenetic relationship. The International Committee of Systematic Bacteriology recommended minimal standards for valid publication of a new taxa according to which the genus should be built on the numerical analysis of physiological and metabolic features and sequence analysis of $16 \mathrm{~S}$ rRNA gene whereas, bacterial species should be diagnosable by a discriminative phenotypic properties and DNA-DNA relatedness (Rosselló-Mora and 
Amann 2001). All studied A. glycyphyllos nodule bacteria were effective in nitrogen-fixation with their original host. Effective symbiosis was by the pink color of root nodules and good growth of plants inoculated with bacteria on nitrogen-free medium for 6 weeks (data not presented). Due to a nitrogen-fixing capacity of studied nodule bacteria, their host- $A$. glycyphyllos can colonize nitrogen deficient areas enhancing their fertility and additionally, A. glycyphyllos-Rhizobium association, potentially is a good candidate for revegetation program.

Phenotypic characterization and numerical classification of A. glycyphyllos nodulators

A total 62 bacterial strains, including 28 A. glycyphyllos nodule isolates and 34 reference strains representing species of the genera: Rhizobium, Ensifer, Mesorhizobium, and Bradyrhizobium were analyzed by using 86 phenotypic properties. The phenotypic characterization of A. glycyphyllos rhizobia was based on their: generation time, utilization of different compounds as a sole carbon and nitrogen sources, tolerance to $\mathrm{NaCl}$, resistance to different antibiotics and stains, litmus milk reaction, temperature and $\mathrm{pH}$ growth range as well as production of some exoenzymes. The liquorice milkvetch rhizobia are Gramnegative, motile bacteria. The bacterial motility was determined on $0.35 \%$ YEM agar medium by flares of growth away from inoculation point (Fig. 1). Temperature is one of the factors affecting the growth of microorganisms. The growth temperature range for $A$. glycyphyllos symbionts was determined between 15 and $34{ }^{\circ} \mathrm{C}$ with typical for most rhizobia optimal temperature 28-30 ${ }^{\circ} \mathrm{C}$ (Elkan 1992; Jarvis et al. 1997; Małek and Sajnaga 1999; Mierzwa et al. 2009). All of them grew at $\mathrm{pH}$ 6-9. None of tested strains could grow at $\mathrm{pH} 5$ but some of them grew at $\mathrm{pH} 10$. Liquorice milkvetch rhizobia could grow on YEM medium with $0.5 \% \mathrm{NaCl}$ and most of them also tolerated $1 \%$ sodium chloride. A. glycyphyllos nodulators were moderately fast-growing rhizobia with generation time $4-6 \mathrm{~h}$ in YEM broth at $28^{\circ} \mathrm{C}$. Such doubling time is a characteristic of the strains of the genus Mesorhizobium (Jarvis et al. 1997; Mierzwa et al. 2009; Van Berkum and Eardly 1998). The strains under investigation were able to use a wide variety of compounds as a sole carbon source. Their carbon utilization patterns varied widely. 14 of the 33 carbon

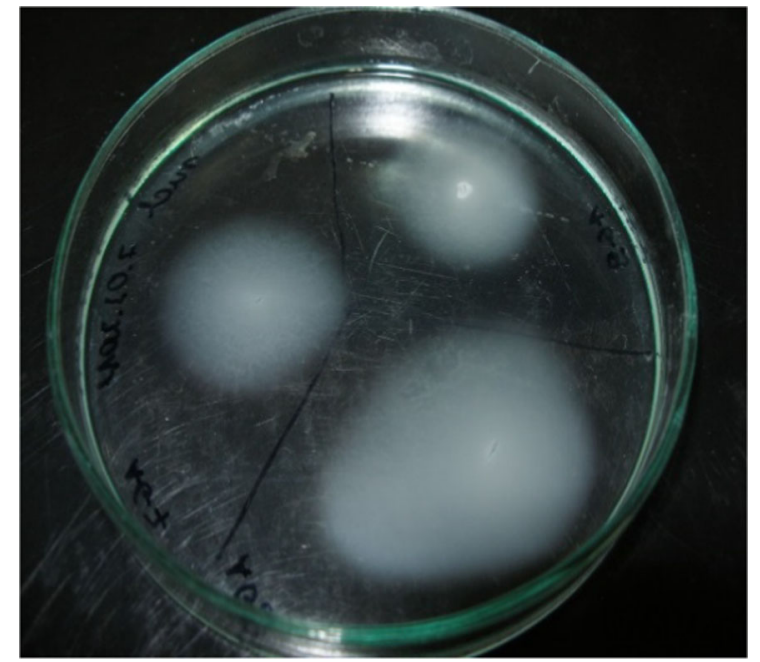

Fig. 1 Light microscopy of swarming motility of A. glycyphyllos symbionts: AG on $0.35 \%$ swim YEM agar sowing a diffuse swim ring expending beyond the site of bacteria inoculation

compounds tested supported the growth of all $28 \mathrm{~A}$. glycyphyllos nodulators. None of them used sodium hippurate as a sole carbon source. Growing on mannitol and different sugars they acidified medium similar as fast growing rhizobia including mesorhizobia (Elkan 1992). Liquorice milkvetch symbionts assimilated di- and trisaccharides: cellobiose, lactose, maltose, raffinose, and sucrose similar as the reference Mesorhizobium species. According to Elkan (1992), this ability is characteristic of fast-growing rhizobia and allow to differentiate them from slow-growing bradyrhizobia. The ability to use a wide range of carbon sources is beneficial for the bacteria living in the soil and may be related to their high competitiveness in a natural environment. Among A. glycyphyllos rhizobia some variations in the assimilation of different nitrogen sources were observed. Nine of 22 nitrogen compounds were used by all studied isolates and only L-glycine and DL-isoleucine were not utilized by any of them. The relevant phenotypic characteristics that differentiate newly discovered A. glycyphyllos rhizobia from reference Mesorhizobium species are listed in Table 2. The growth of A. glycyphyllos rhizobia, in the presence of six antibiotics and eight different stains was also tested. These bacteria indicated different patterns for resistance to antibiotics, however, their spectrum of intrinsic antibiotic resistance was relatively narrow. Studied isolates showed a week resistance to tetracycline, neomycin and 


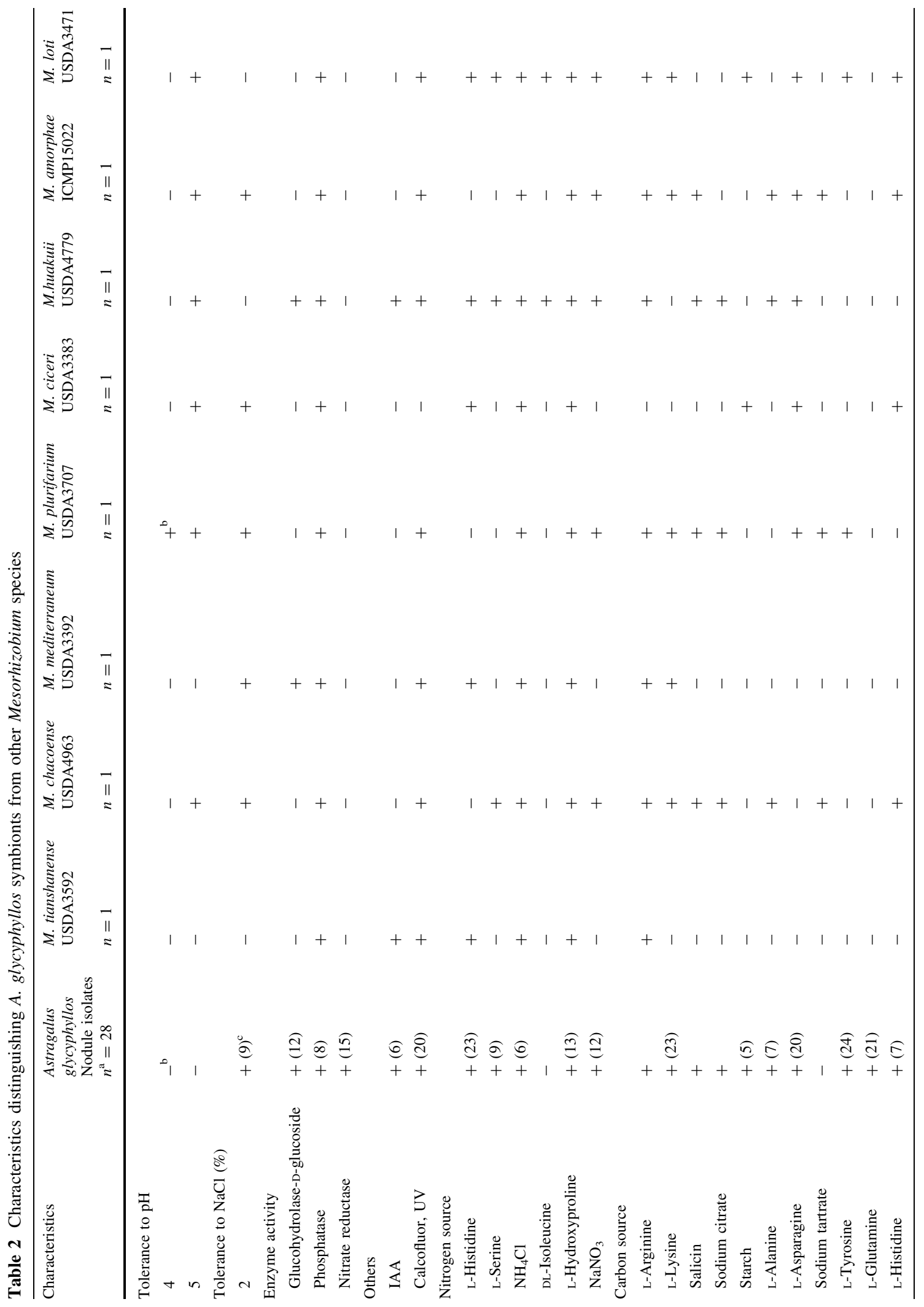




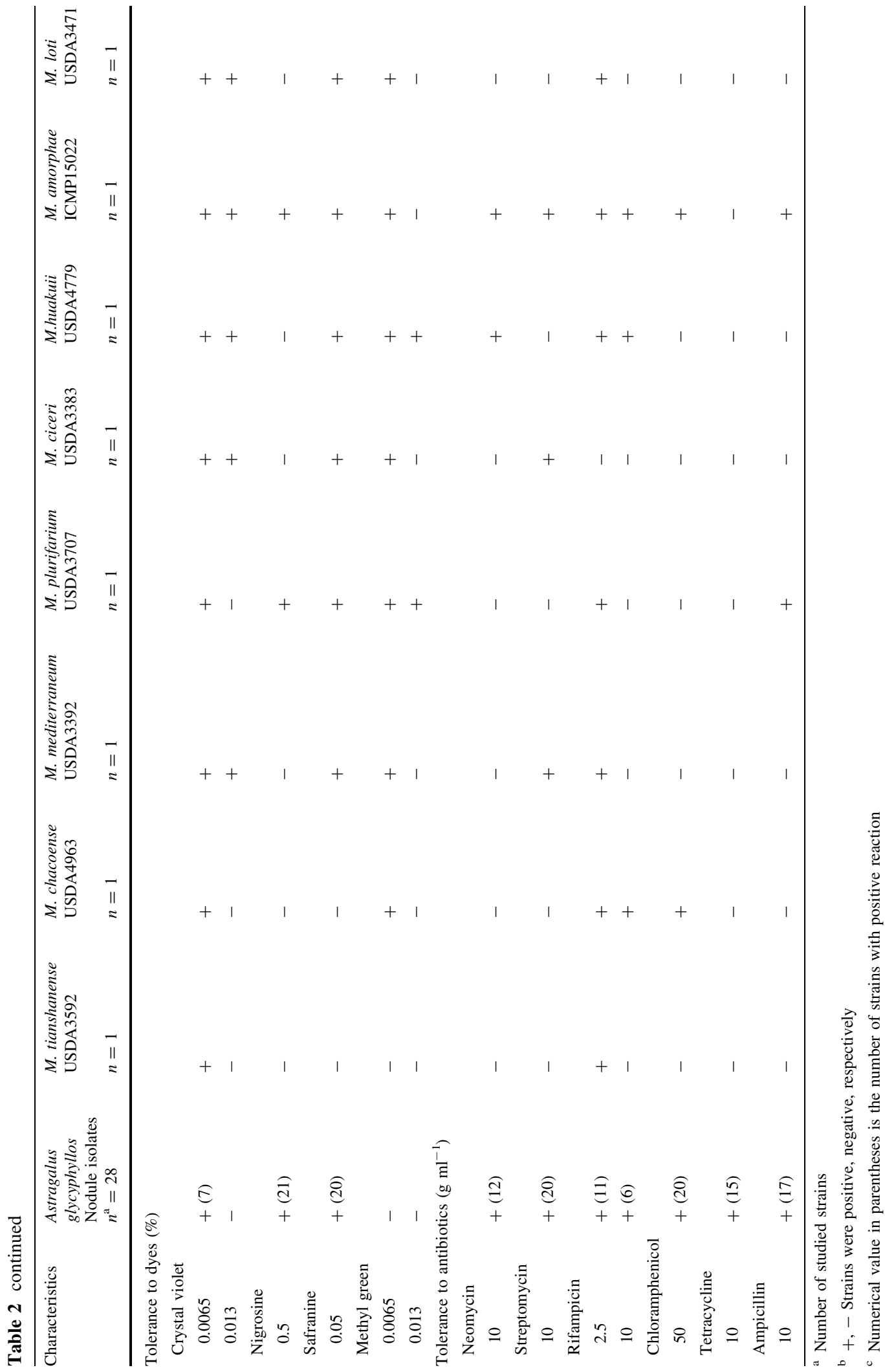

\section{Springer}


ampicillin $\left(5-10 \mu \mathrm{g} \mathrm{ml}^{-1}\right)$. They were very susceptible to rifampicin $\left(2.5 \mu \mathrm{g} \mathrm{ml}^{-1}\right)$ and only part of them was resistant to chloramphenicol as well as streptomycin $\left(100 \mu \mathrm{g} \mathrm{ml}^{-1}\right)$. It was found that the susceptibility level of A. glycyphyllos nodule isolates to antibiotics was similar to that in fast-growing nodule bacteria of the genera Mesorhizobium, Rhizobium, and Ensifer (Elkan 1992; Garrity et al. 2002; Małek and Sajnaga 1999). For classification and identification of bacteria biochemical tests are also very helpful. They indicated that liquorice milkvetch rhizobia produce acids during the growth in the litmus milk. $A$. glycyphyllos rhizobia showed cytochrome oxidase activity, most of them reduced nitrate to nitrite but any of them could further reduce nitrite to gaseous nitrous oxide. In many strains catalase and urease were expressed but $\beta$-galactosidase was not detected.

The phenotypic features, which differentiated strains included into the studies were used for numerical analysis. The results of this cluster analysis, performed by the unweighted pair group method using arithmetic averages, are shown in Fig. 2. All examined nodule bacteria were divided into two major groups at similarity level of $67 \%$ and one independent lineage comprising $R$. galegae strains which branched far from all other tested bacteria. One cluster consisted of fast growing species of the genera: Ensifer, Rhizobium (except for R. galegae), and Mesorhizobium as well as A. glycyphyllos nodule isolates whereas second one comprised slow-growing bacteria of the genus Bradyrhizobium. In the cluster comprising fast-growing rhizobia, all 28 A. glycyphyllos nodule isolates formed one large taxonomic subgroup at SM of 0.76 . They were found to be closely related to the reference bacteria of the genus Mesorhizobium and formed with them one phenon at the similarity level of $75 \%$. This phenon was clearly separated from cluster comprising Rhizobium and Ensifer species (Fig. 2). The fact that liquorice milkvetch rhizobia and Mesorhizobium species grouped together in one phenon at coefficient similarity of 0.75 preliminary indicates that studied $A$. glycyphyllos nodulators belong to the genus Mesorhizobium. We also suggest that large phenotypic diversity of the studied A. glycyphyllos-Rhizobium population, assessed by numerical analysis, may be essential attribute for its good survival under different environmental conditions and may contribute to the adaptation of these bacteria to the changing soil conditions.
16S rDNA sequencing and analysis

Analysis of $16 \mathrm{~S}$ rDNA sequences is widely used to define the taxonomic position and tracing evolutionary history of nodule bacteria (Kalita and Małek 2010; Mierzwa et al. 2010; Shamseldin et al. 2013; Vinay et al. 2013; Vinuesa et al. 2005; Wdowiak-Wróbel and Małek 2010). In order to clarify the taxonomic status and the phylogenetic relationship of A. glycyphyllos nodule isolates and other rhizobia, PCR amplification and sequencing of nearly full-length $16 \mathrm{~S}$ rRNA gene (1,239 bp long) of ten symbionts, representing different phena of liquorice milkvetch rhizobia were performed. 16S rDNA sequences were aligned and compared with those of other rhizobia available in the GenBank database. Evolutionary distances between $A$. glycyphyllos rhizobia and reference bacteria were calculated and molecular phylogeny was reconstructed using the ML and NJ methods (Kimura 1980; Posada and Crondall 1998). The phylogenetic relationships between the studied, yet unclassified rhizobia and the previously named species belonging to the genera: Mesorhizobium, Rhizobium, Ensifer, Bradyrhizobium, and Azorhizobium is presented only as the ML dendrogram (Fig. 3) since the bacterial clusters strongly supported by the ML distance method were not contradicted by NJ method and vice versa. The results from comparative $16 \mathrm{~S}$ rDNA sequence studies (Fig. 3) confirmed those from numerical analysis of phenotypic properties (Fig. 2). None of the $16 \mathrm{~S}$ rDNA sequences of A. glycyphyllos nodulators and those of reference rhizobia included into analysis were identical. Their pairwise lowest and highest level of $16 \mathrm{~S}$ rDNA sequence similarity was 85 and $99 \%$, respectively. The 16S rDNA sequences of novel isolates also does not perfectly match each other and they were determined to share 95-99\% identical sequences. The meso-growing A. glycyphyllos rhizobia were phylogenetically very close to Mesorhizobium species with 16S rDNA sequence divergence between 1 and $5 \%$. It is known that $95 \%$ and higher sequence identities in 16S rDNA sequences serve as "gold standard" for bacterial classification at the genus level (Graham et al. 1991; Madhaiyan and Poonguzhali 2014; Mierzwa et al. 2009; Rosselló-Mora and Amann 2001; Stackebrandt and Goebel 1994; Vandamme et al. 1996; Willems and Collins 1993). Based on the 16S rDNA sequence analysis, A. glycyphyllos nodulating rhizobia were assigned to the genus Mesorhizobium. The level 
Fig. 2 UPGMA dendrogram showing phenotypic relationship between A. glycyphyllos rhizobia and reference strains

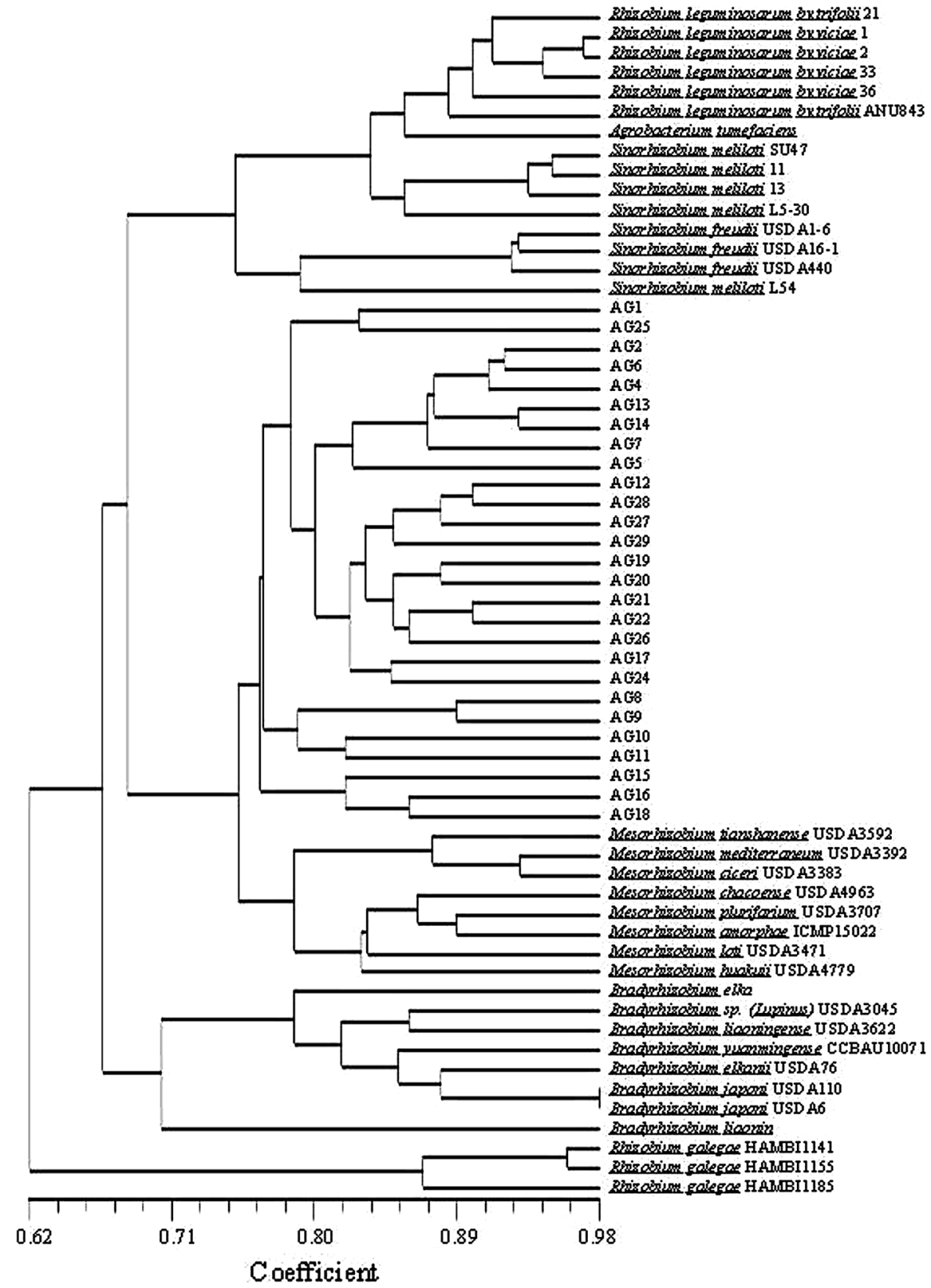

of nucleotide sequence similarity between the $16 \mathrm{~S}$ rDNA of A. glycyphyllos symbionts and those of Rhizobium, Ensifer, Bradyrhizobium and Azorhizobium species were 90-93, 91-95, 85-87 and 87-90\%, respectively. Bacteria of the Rhizobium, Ensifer, Bradyrhizobium and Azorhizobium genera formed on the 16S rDNA phylogram separate, monophyletic lineages with Bradyrhizobium species and Azorhizobium caulinodans as an outliers (Fig. 3).
On the $16 \mathrm{~S}$ rDNA phylogram, all novel rhizobia clustered together with the Mesorhizobium species with high confidence (95\% bootstrap) and they were divided into two subgroups (Fig. 3). One of them consisted of Mesorhizobium tianshanense CCNWXJ0216, Mesorhizobium temperatum SDW018, Mesorhizobium mediterraneum PECA20, Mesorhizobium chacoense PR5, Mesorhizobium ciceri SEMIA396, and A. glycyphyllos nodulators: AG1, AG5, AG7, AG9, AG15, AG27. The 
Fig. 3 Maximum likelihood tree displaying the phylogenetic relationship of $A$. glycyphyllos symbionts to other rhizobia based on $16 \mathrm{~S}$ rRNA gene sequences (GenBank accession numbers of $16 \mathrm{~S}$ rDNA sequences from this study are given in parenthesis after the name of $A$. glycyphyllos symbionts)

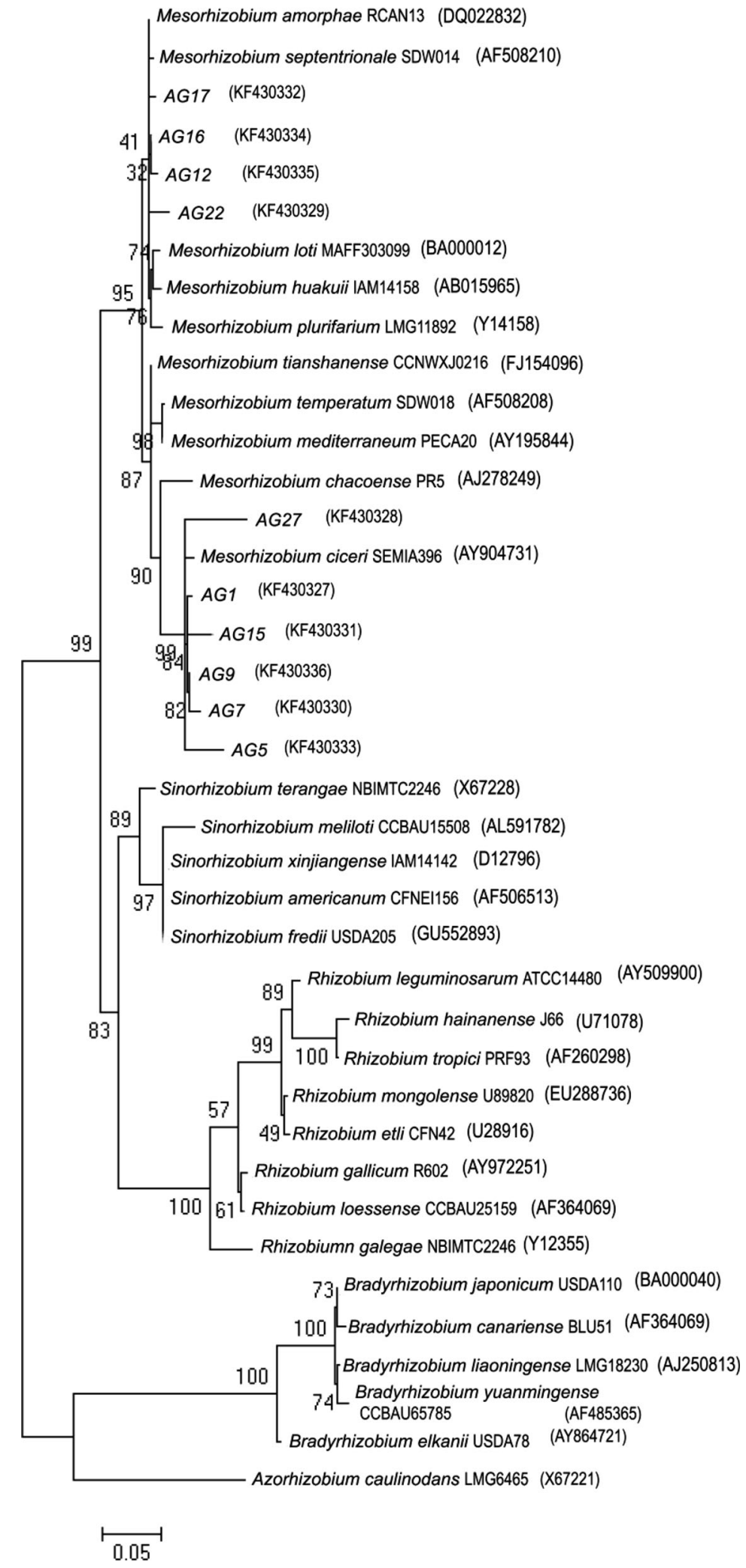




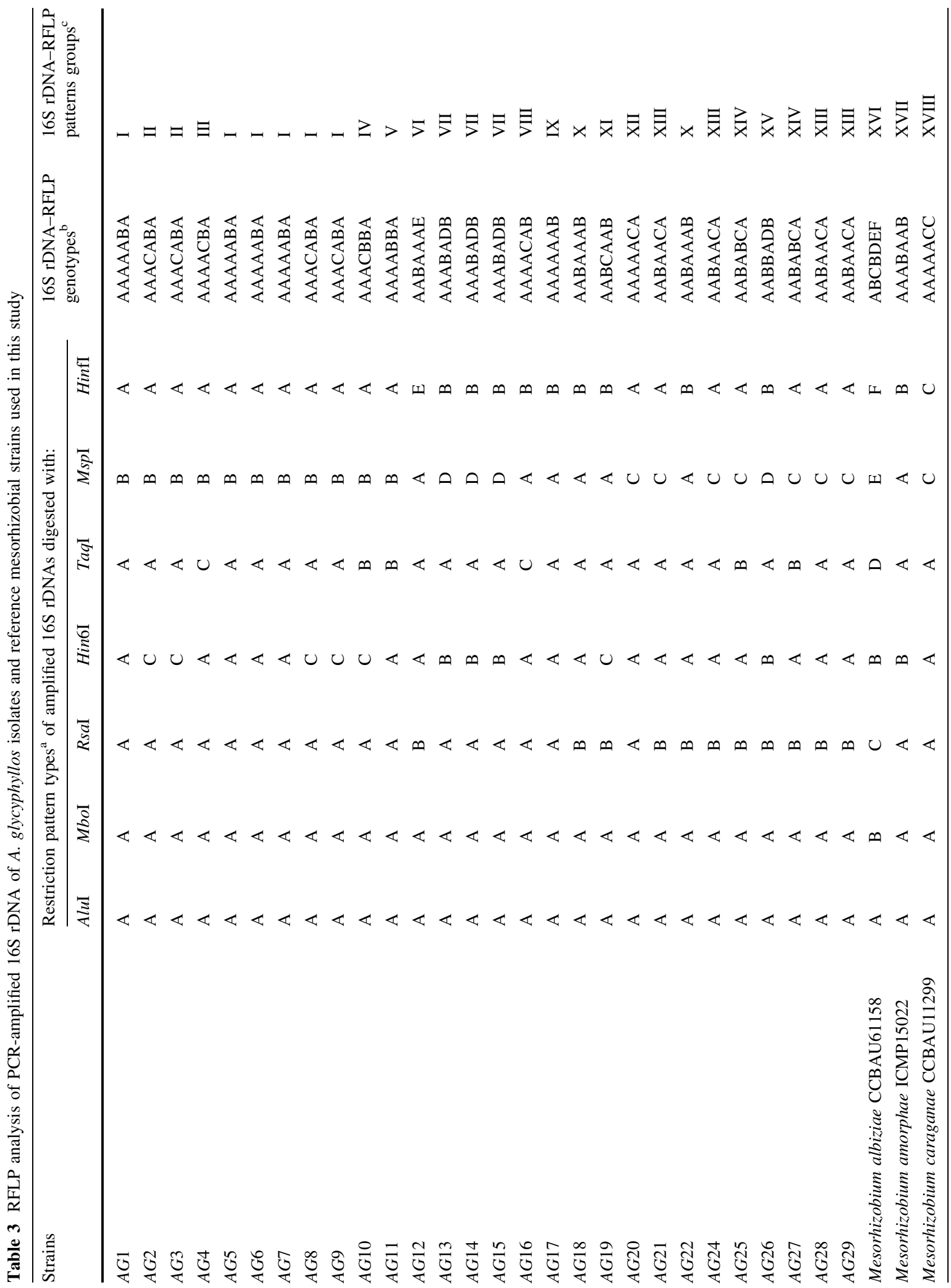




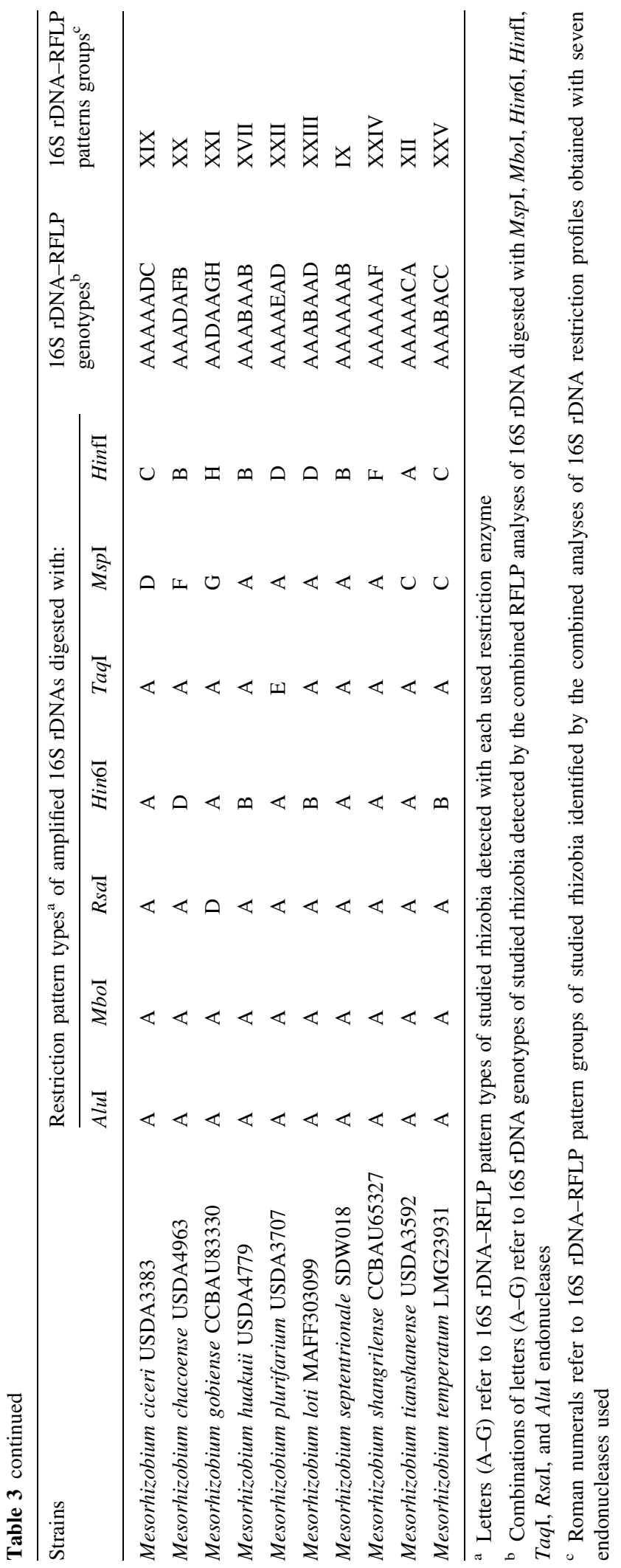




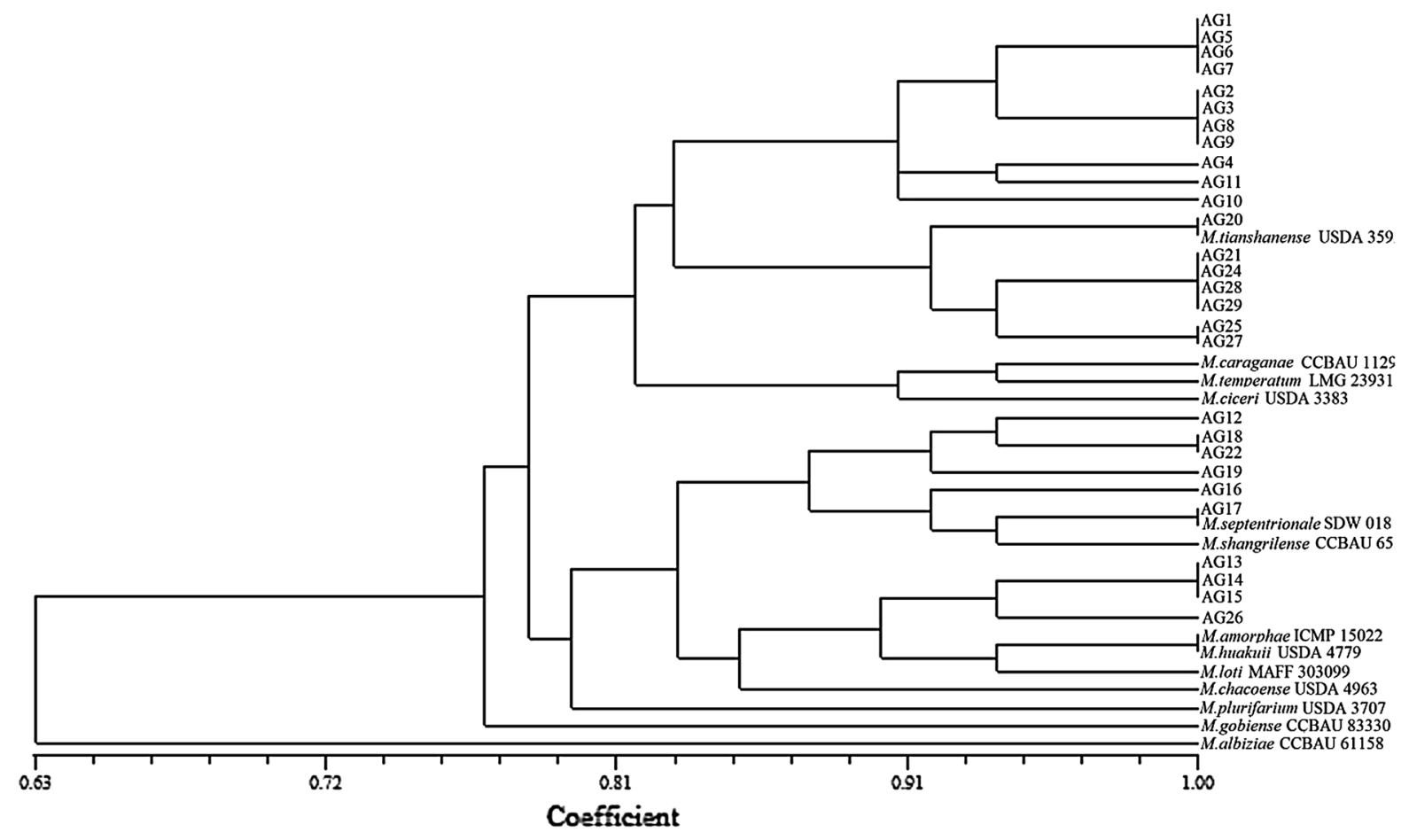

Fig. 4 Dendrogram based on the UPGMA cluster analysis of RFLP patterns of 16S rDNA showing phylogenetic relationship of $A$. glycyphyllos symbionts and reference mesorhizobia

second subgroup comprised: Mesorhizobium amorphae RCAN13, Mesorhizobium septentrionale SDW014, Mesorhizobium loti MAFF303099, Mesorhizobium huakuii IAM14158, Mesorhizobium plurifarium LMG11892 as well as liquorice milkvetch symbionts: AG12, AG16, AG17, and AG22 (Fig. 3).

\section{RFLP analysis of PCR amplified 16S RNA genes}

RFLP analysis of $16 \mathrm{~S}$ rDNA is recognized as a powerful and rapid method to determine the phylogenetic relationship of large number of legume root nodule isolates (Kalita and Małek 2010; Mierzwa et al. 2010; Shamseldin et al. 2013; Sikora and Redžepović 2003; Vinay et al. 2013; Vinuesa et al. 2005; Woldemeskel et al. 2005). To elucidate the phylogeny and genus position of all 28 A. glycyphyllos nodule isolates, fingerprinting of $16 \mathrm{~S}$ rDNA by RFLP has been used. The $16 \mathrm{~S}$ rDNAs of liquorice milkvetch rhizobia as well as those of reference bacteria of the genus Mesorhizobium were amplified via PCR with universal primers fD1 and rD1 (Weisburg et al. 1991). Amplification provided for each studied strain a single band of about $1,5 \mathrm{~kb}$ long. The PCR products were digested separately by seven 4-base cutting enzymes and the resulting fragments were separated by electrophoresis (data not presented). Two enzymes (AluI and $M b o \mathrm{I}$ ) did not established different RFLP patterns for A. glycyphyllos nodule isolates and produced the same 16S rDNA profile for all of them. Remaining five endonucleases (MspI, TaqI, Hin6I, RsaI, HinfI) differentiated studied isolates and established specific to them 16S rDNA-RFLP patterns. AluI produced identical DNA profiles for A. glycyphyllos symbionts and reference rhizobia, whereas HinfI was the most discriminating restriction enzyme for these bacteria and was able to differentiate among them eight restriction pattern types. The remaining enzymes produced the following number of profiles: 5, TaqI; 4, Hin6I; 8, RsaI. The 16S rDNA-RFLP patterns of $A$. glycyphyllos nodule isolates were compared with those of the genus Mesorhizobium reference strains. The 16S rDNA-RFLP profiles of studied rhizobia, obtained in two independent experiments, were very similar (data not presented). Based on the combined RFLP patterns of $16 \mathrm{~S}$ rRNA gene, 25 distinct $16 \mathrm{~S}$ rDNA genotypes were distinguished within all 41 analyzed strains (13 among 28 isolates collected from 
A. glycyphyllos nodules and 12 among 13 reference Mesorhizobium species) (Table 3). Our results supported previous reports on heterogeneous nature of the genus Mesorhiozobium strains (Mierzwa et al. 2009; Wang et al. 1999, 2007; Wdowiak-Wróbel and Małek 2010). Among studied A. glycyphyllos symbionts, the most widespread was genotype designated as: I which comprised six strains. Five other genotypes i.e. XIII, VII, II, X, and XIV occurred less frequently in liquorice milkvetch Rhizobium population and were represented by four, three, two, two, and two strains, respectively. Nine genotypes were specific to single $A$. glycyphyllos nodulators. Two of them, 16S rDNA genomic types IX (strain AG17) and XII (strain AG20) showed the $16 \mathrm{~S}$ rDNA restriction patterns identical to those of M. septentrionale SDW018 and M. tianshanense USDA3592, respectively (Table 3).

The fingerprints of bacterial strains generated by RFLP of 16S rRNA genes were used for a cluster analysis and construction of the dendrogram according to the genetic distance matrix by the UPGMA algorithm. The close phylogenetic relationship of $A$. glycyphyllos symbionts and the genus Mesorhizobium bacteria is presented on the $16 \mathrm{~S}$ rDNA-RFLP phylogram (Fig. 4). All A. glycyphyllos nodulators clustered together with Mesorhizobium species forming two coherent subgroups at 16S rDNA-RFLP pattern similarities of $\sim 82-83 \%$. Only $M$. gobiense and $M$. albiziae branched off from the remaining bacteria included into analysis and formed a separate phylogenetic lineages with $16 \mathrm{~S}$ rDNA-RFLP similarity patterns to them of 77 and $63 \%$, respectively (Fig. 4). Results obtained in RFLP analysis of 16S rDNA correlated well with those of $16 \mathrm{~S}$ rDNA sequence analysis. The composition of A. glycyphyllos nodulators within two main clusters on the phylograms constructed by $16 \mathrm{~S}$ rDNA sequences (Fig. 3) and RFLP analyses (Fig. 4) was identical (with exception of AG15 strain). These data led us to conclusion that combine analysis of $16 \mathrm{~S}$ rDNA-RFLP patterns is a powerful approach for rapid typing and classification of large number of legume root nodule isolates at the genus level.

In conclusion, in the present study by using numerical analysis of phenotypic properties, RFLP and sequence analyses of $16 \mathrm{~S}$ rDNA we showed that A. glycyphyllos nodule bacteria were grouped within the genus Mesorhizobium cluster lending strong support to classify the liquorice milkvetch rhizobia in the genus Mesorhizobium.

Acknowledgments This research was supported by the Grant from the National Science Centre Poland: 2011/03/B/NZ8/ 02142 .

Open Access This article is distributed under the terms of the Creative Commons Attribution License which permits any use, distribution, and reproduction in any medium, provided the original author(s) and the source are credited.

\section{References}

Allen ON, Allen EK (1981) The Leguminosae, a source book of characteristics, uses, and nodulation. University of Wisconsin Press, Madison

Balachandar D, Raja P, Kumar K, Sundaram SP (2007) Nonrhizobial nodulation in legumes. Biotechnol Mol Biol Rev 2:049-057

Cowan ST, Steel KJ (1965) Manual for the identification of medical bacteria. University Press, Cambridge

Cubo MT, Buendia-Claveria AM, Beringer JE, Ruiz-sainz J (1998) Melanin production by Rhizobium strains. Appl Environ Microbiol 54:1812-1817

Elkan GH (1992) Taxonomy of the rhizobia. Can J Microbiol 38:446-450

Garrity GM, Winters M, Kuo AW, Searles DB (2002) Taxonomic outline of the prokaryotes Bergey's manual of systematic bacteriology, 2nd edn. Springer, New York

Graham PH, Sadowsky MJ, Keiser HH et al (1991) Proposed minimal standards for the description of new genera and species of root and stem-nodulating bacteria. Int $\mathrm{J}$ Syst Bacteriol 41:582-587

Haag AF, Markus FF, Arnold MFF, Myka KK, Kerscher B, Dall'Angelo S, Matteo Zanda M, Mergaert PP, Gail P, Ferguson GP (2013) Molecular insights into bacteroid development during Rhizobium-legume symbiosis. FEMS Microbiol Rev 37:364-383

Hofer AW (1941) A characterization of Bacterium radiobacter (Beijerinck and Van Delden) Löhnis. J Bacteriol 41: 193-224

Jarvis BDW, van Berkum P, Chen WX, Nour SM, Fernandez MP, Cleyet-Marel JC, Gillis M (1997) Transfer of Rhizobium loti, Rhizobium huakuii, Rhizobium ciceri, Rhizobium mediterraneum, and Rhizobium tianshanense to Mesorhizobium gen. nov. Int J Syst Bacteriol 47:895-898

Kalita M, Małek W (2004) Phenotypic and genomic characteristics of rhizobia isolated from Genista tinctoria root nodules. Syst Appl Microbiol 27:707-715

Kalita M, Małek W (2010) Genista tinctoria microsymbionts from Poland are new members of Bradyrhizobium japonicum bv. genistearum. Syst Appl Microbiol 33:252-259

Kimura M (1980) A simple method for estimating evolutionary rates of base substitutions through comparative studies of nucleotide sequences. J Mol Evol 16(2):111-120 
Madhaiyan M, Poonguzhali S (2014) Methylobacterium pseudosasae sp. nov., a pink-pigmented, facultatively methylotrophic bacterium isolated from the bamboo phyllosphere. Antonie Van Leeuwenhoek 105:367-376

Małek W, Sajnaga E (1999) Current taxonomy of the rhizobia. Acta Microbiol Pol 48:109-122

Mierzwa B, Wdowiak-Wróbel S, Małek W (2009) Phenotypic, genomic and phylogenetic characteristics of rhizobia isolated from root nodules of Robinia pseudoacacia (black locust) growing in Poland and Japan. Arch Microbiol 191:697-710

Mierzwa B, Wdowiak-Wróbel S, Małek W (2010) Robinia pseudoacacia in Poland and Japan is nodulated by Mesorhizobium amorphae strains. Antonie Van Leeuwenhoek 97:351-361

Minamisawa K, Fukai K (1991) Production of indole-3-acetic acid by Bradyrhizobium japonicum: a correlation with genotype grouping and rhizobiotoxin production. Plant Cell Physiol 32:1-9

Nei M, Li WH (1979) Mathematical model for studying genetic variations in terms of restriction endonucleases. Proc Natl Acad Sci USA 76:52-69

Parte AC (2014) LPSN-list of prokaryotic names with standing in nomenclature. Nucleic Acids Res 42:D613-D616. doi:10.1093/nar/gkt1111

Perret X, Staehelin C, Broughton WJ (2000) Molecular basis of symbiotic Promiscuity. Microbiol Mol Biol Rev 64:180-201

Pitcher DG, Saunders NA, Owen RJ (1989) Rapid extraction of bacterial genomic DNA with guanidium thiocyanate. Lett Appl Microbiol 8:151-156

Posada D, Crondall KA (1998) Modeltest: testing the model of DNA substitution. Bioinformatics 14:817-818

Rosselló-Mora R, Amann R (2001) The species concept for prokaryotes. FEMS Microbiol Rev 25:39-67

Safronova VI, Kimeklis A, Chizhevskaya EP, Belimov AA, Andronov EE, Pinaev AG, Pukhaev AR, Popov KP, Tikhonovich IP (2014) Genetic diversity of rhizobia isolated from nodules of the relic species Vavilovia formosa (Stev.) Fed. Antonie Van Leeuwenhoek 105:389-399

Sawada H, Kuykendall LD, Young JM (2003) Changing concepts in the systematics of bacterial nitrogen-fixing legume symbionts. J Gen Appl Microbiol 49:155-179

Shamseldin A, Moawad H, Abd El-Rahim WM, Sadowsky MJ (2013) Near-full length sequencing of 16S rDNA and RFLP indicates that Rhizobium etli is the dominant species nodulating Egyptian winter Berseem clover (Trifolium alexandrinum L.). Syst Appl Microbiol. doi:10.1016/j. syapm.2013.08.002

Sherwood MT (1970) Improved synthetic medium for the growth of Rhizobium. J Appl Bacteriol 33:708-713

Sikora S, Redžepović S (2003) Genotypic characterization of indigenous soybean rhizobia by PCR-RFLP of $16 \mathrm{~S}$ rDNA, rep-PCR and RAPD analysis. Food Technol Biotechnol 41:61-67

Smibert RM, Krieg N (1981) Systematics: general characterization. In: Gerhardt P, Murray RGE, Costilow RN, Nester EW, Wood WA, Krieg NR, Phillips GB (eds) Manual of methods for general bacteriology. American Society for Microbiology, Washington, DC, pp 409-443

Sneath PA, Sokal R (1973) Principles of numerical taxonomy. Freeman and Co., San Francisco
Stackebrandt E, Goebel BM (1994) Taxonomic note: a place for DNA:DNA reassociation and $16 \mathrm{~S}$ rRNA sequence analysis in the present species definition in bacteriology. IJSB 4(4): 846-849

Swofford DL (2002) PAUP*. Phylogenetic analysis using parsimony (*and other methods). Sinauer Associates, Sunderland

Tamura K, Dudley J, Nei M, Kumar S (2007) MEGA4: Molecular Evolutionary Genetics Analysis (MEGA) Software Version 4.0. Mol Biol Evol 24(8):1596-1599

Toolarood SA, Alikhani HA, Asadi-Rahmani H, Salehi Gh, Khavazi K, Poorbabaee AA, Lindström K (2012) Molecular diversity of rhizobia isolated from root nodules of alfalfa evaluated by analysis of IGS and 16S rRNA. Ann Biol Res 3(5):2058-2063

Van Berkum P, Eardly BD (1998) Molecular evolutionary systematics of the Rhizobiaceae. In: Spaink H, Kondorosi A, Hooykass PIJ (eds) The Rhizobiaceae. Kluwer Academic Publishers, Dordrecht, pp 1-24

Vandamme P, Pot B, Gillis M, de Vos P, Kersters K, Swing J (1996) Polyphasic taxonomy, a consensus approach to bacterial systematics. Microbiol Rev 60:407-438

Vinay O, Bhupendra P, Kiran S (2013) 16S rDNA-RFLP analysis of phylogenetic tree of Rhizobium bacteria. Microbiology 12(3):474-476

Vincent J (1970) A manual for the practical study of root nodule bacteria. Blackwell Scientific Publication Ltd., Oxford

Vinuesa P, Silva C, Lorite J, Izaguirre-Mayoral ML, Bedmar EJ, Martinez-Romero E (2005) Molecular systematics of rhizobia based on maximum likelihood and Bayesian phylogenies inferred from rrs, atpD, recA and nifH sequences, and their use in the classification of Sesbania microsymbionts from Venezuelan wetlands. Syst Appl Microbiol 28:702-716

Wang ET, van Berkum P, Sui XH, Beyene D, Chen WX (1999) Diversity of rhizobia associated with Amorpha fruticosa isolated from Chinese soils and description of Mesorhizobium amorphae sp. nov. IJSB 49:51-65

Wang FQ, Wang ET, Liu J, Chen Q, Sui XH, Chen WF, Chen WX (2007) Mesorhizobium albiziae sp. nov., a novel bacterium that nodulates Albizia kalkora in a subtropical region of China. IJSEM 57:1192-1197

Wdowiak-Wróbel S, Małek W (2000) Numerical analysis of Astragalus cicer microsymbionts. Curr Microbiol 41: 142-148

Wdowiak-Wróbel S, Małek W (2010) Following phylogenetic tracks of Astragalus cicer microsymbionts. Antonie Van Leeuwenhoek 97:21-34

Weisburg WG, Barns SM, Pelletier DA, Lane DJ (1991) 16S ribosomal DNA amplification for phylogenetic study. J Bacteriol 173:697-703

Willems A (2006) The taxonomy of rhizobia: an overview. Plant Soil 287:3-14

Willems A, Collins MD (1993) Phylogenetic analysis of rhizobia and agrobacteria based on 16S rRNA gene sequences. Int J Syst Bacterial 43:305-313

Wolde-meskel E, Terefework Z, Frostegard A, Lingstram K (2005) Genetic diversity and phylogeny of rhizobia isolated from agroforestry legume species in southern Ethiopia. Int J Syst Evol Microbiol 55:1439-1452 